\title{
Is the intraoperative air leak test effective in the prevention of colorectal anastomotic leakage? A systematic review and meta-analysis
}

\author{
Zhouqiao $\mathrm{Wu}^{1,2}$ - Remondus C. J. van de Haar ${ }^{2}$ Cloë L. Sparreboom ${ }^{2}$. \\ Geesien S. A. Boersema ${ }^{2} \cdot$ Ziyu Li $^{1} \cdot{\text { Jiafu } \mathrm{Ji}^{1}}^{1}$ Johannes Jeekel $^{3} \cdot$ Johan F. Lange $^{2,4}$
}

Accepted: 3 June 2016 / Published online: 13 June 2016

(C) The Author(s) 2016. This article is published with open access at Springerlink.com

\begin{abstract}
Objective The intra-operative air leak test (ALT) is a common intraoperative test used to identify mechanically insufficient anastomosis. This meta-analysis aims to determine whether ALT aids to the reduction of postoperative colorectal anastomotic leakage (CAL).

Methods A literature search was performed to select studies in acknowledged databases. Full text articles targeting ALT during colorectal surgery were included. Quality assessment, risk of bias, and the level-of-evidence of the inclusions were evaluated. ALT methodology, ALT(+) (i.e., leak observed during the test) rate, and postoperative CAL rate of the included studies were subsequently analyzed.

Results Twenty studies were included for analysis, in which we found substantial risks of bias. A lower CAL rate was observed in patients who underwent ALT than those did not; however, the difference was not significant $(p=0.15)$. The intraoperative $\operatorname{ALT}(+)$ rate greatly varied among the included studies from 1.5 to $24.7 \%$. ALT(+) patients possessed a significantly higher CAL rate than the ALT(-) patients (11.4 vs. $4.2 \%, p<0.001)$.
\end{abstract}

Zhouqiao $\mathrm{Wu}$

wuzhouqiao@gmail.com

1 Department of Gastrointestinal Surgery, Peking University Cancer Hospital \& Institute, No. 52, Fu-Cheng Road, Hai-Dian District, Beijing 100142, China

2 Department of Surgery, Erasmus University Medical Center, Rotterdam, The Netherlands

3 Department of Neuroscience, Erasmus University Medical Center, Rotterdam, The Netherlands

4 Department of Surgery, Havenziekenhuis, Rotterdam, The Netherlands
Conclusions Based on the available evidence, performing an ALT with the reported methodology has not significantly reduced the clinical CAL rate but remains necessary due to a higher risk of CAL in ALT(+) cases. Unfortunately, additional repairs under current methods may not effectively decrease this risk. Results of this review urge a standardization of ALT methodology and effective methods to repair ALT $(+)$ anastomoses.

Keywords Anastomotic leakage $\cdot$ Colorectal surgery $\cdot$ Air leak test $\cdot$ Prevention

\section{Introduction}

Colorectal anastomotic leakage (CAL) is one of the most dangerous short-term complications after colorectal surgery, attributing to one third of postoperative mortality [1]. To prevent CAL, substantial efforts have been made. Among them, the air leak test (ALT) is apparently the most frequently performed intraoperative test to identify a mechanically insufficient anastomosis [2]. Typically, certain countermeasures such as additional sutures or a temporary protective stoma construction are performed when a leak (e.g., leakage of air bubbles or dye) was observed during the test.

Though being performed by a majority of colorectal surgeons, it remains inconclusive whether performing ALT and the immediate repair of the ALT $(+)$ cases (i.e., leak of air/dye observed in the test) is beneficial in preventing CAL. This may be due to at least two variables: first, the etiology of CAL is multi-factorial, comprised of communication between intra- and extra-luminal content (e.g., suture dehiscence), anastomotic infection (e.g., peritonitis) and healing disturbances (e.g., ischemia). Performing an ALT may provide limited assistance in detecting CAL due to causes other than 
anastomotic mechanical failure. Second, various ALT techniques with different outcomes have been reported, which increases the concern that whether such varying techniques may cause different results in detecting mechanically failed anastomosis and eventually lead to different clinical intervention and outcomes. To date, no systematic review or metaanalysis is available to provide solid evidence to support a routine ALT application. To this end, we performed this review aiming to determine whether implementing the intraoperative air leak test might aid to reduce CAL.

\section{Method}

\section{Literature search strategy}

The literature search for this systematic review was performed in January 2015 according to the PRISMA (Preferred Items for Reporting of Systematic Reviews and Meta-Analyses) guidelines in databases including Medline, Embase, Cochrane, Webof-Science, and Google Scholar databases. No restrictions regarding publication date or language have been applied during the search. We restricted our search to human studies. The following search strategy was used in Embase and modified in other databases accordingly: ((air NEAR/3 (leak* OR pressure* OR insufflat* OR burst* OR tight* OR compress* OR inject* OR deflat $\left.^{*}\right)$ NEAR/3 test*) OR ((( (air OR leak* OR pressure) NEAR/ 3 test*):ab,ti) AND ("anastomosis leakage"/exp OR "intestine anastomosis"/exp OR anastomosis/exp OR (anastomo* OR leak*):ab,ti))) AND ("intestine surgery"/exp OR intestinelexp OR "large intestine disease"/exp OR (intestin* OR colorect* OR colon* OR rectum OR rectal OR bowel* OR sigmoidectom* OR hemicolectom* OR anorectal OR anal OR anus):ab,ti).

\section{Study selection}

Titles and abstracts of identified articles were independently screened by two authors (R.H., C.S.) for relevance to the subject. Full text articles were included if they targeted intraoperative air leak test during colorectal surgery and reported the CAL rate accordingly. Reviews, letters to editors, congress, and meeting abstracts were excluded. Hereafter, the references of the selected articles were screened for any relevant articles.

\section{Quality assessment and data extraction}

Quality assessment and risk of bias were reviewed by two independent authors (R.H., C.S.) according to The Cochrane Collaboration's tool for assessing risk of bias [3]. The tool assesses the risk of bias and applicability concerns by means of six key domains including sequence generation, allocation concealment, blinding, incomplete outcome data, selective outcome reporting, and other sources of bias. Afterwards, the Level of Evidence was evaluated according to the Levels of Evidence (LOE) 2011 from the Centre for Evidence Based Medicine, Oxford [4].

The definition of CAL and the method of performing the air leak test of the included articles were recorded. The clinical endpoints, postoperative clinical or radiological colorectal manifestations of CAL were included for analysis. We assessed ALT performance, intraoperative leakage rate, and the corresponding CAL rates. We also evaluated several subgroups including the analysis of CAL rate in ALT (+) vs. ALT( $(-)$ groups. ALT $(+)$ is defined as leak of air/dye observed in the test; ALT $(-)$ is defined as leak of air/dye not observed in the test.

\section{Statistical analysis}

Our primary objective was to determine whether performing ALT reduces CAL. We made a comparison between CAL rates in patients who underwent ALT vs. CAL rates in patients that did not undergo the test. We also compared the CAL rate in the $\operatorname{ALT}(+)$ patients vs. the $\operatorname{ALT}(-)$ ones to determine whether ALT $(+)$ patients have a higher CAL incidence after surgery. For pooling data and calculating a pooled mean for each outcome, the Mantel-Haenszel method was applied using a random-effect model; mean differences with a $95 \%$ confidence interval were calculated. Statistical heterogeneity was assessed using $Q$ statistic and $I^{2}$ statistics.

\section{Sensitivity analysis}

To assess the individual effect of the studies on the overall outcome, a sensitivity analysis was performed. One study was removed at a time to determine whether this would influence the significance of the pooled outcome.

Analyses were performed using Review Manager software (RevMan version 5.3; The Nordic Cochrane Centre, Copenhagen, Denmark).

\section{Results}

\section{Literature search results, level of evidence, and risk of bias}

In total, there were 500 studies identified during the systematic search, of which, 12 studies appeared to be relevant to the study question and were therefore included for analysis. An additional 8 articles were selected from the references, boosting the total to 20 included articles (Fig. 1). In total, 5283 patients were included for analysis, with 2395 of them undergoing ALT. The inclusions contained 2 randomized trials, 7 cohort studies, and 11 case series (Table 1).

The risk of bias of each inclusion was evaluated and listed in Table 2. Substantial risks of bias were observed 
Fig. 1 Flow chart of the literature search according to the PRISMA guideline

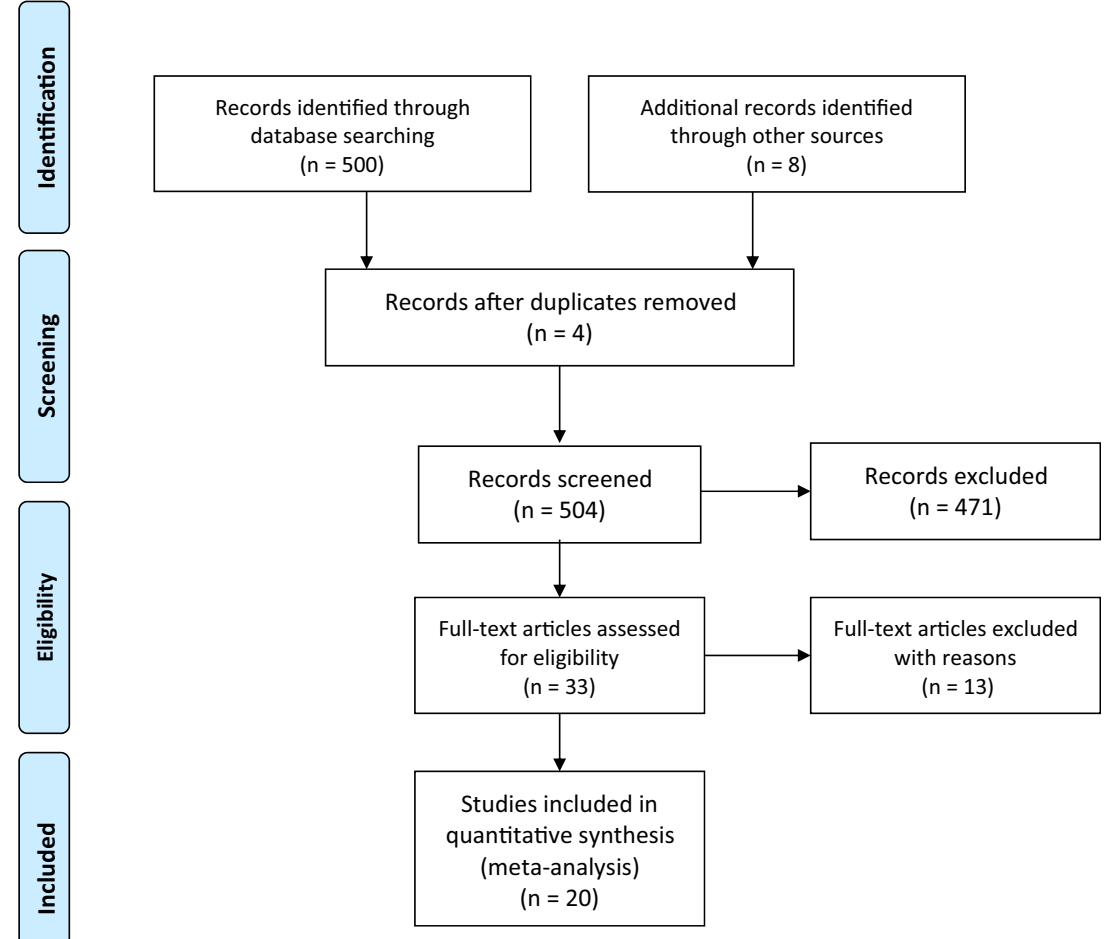

among different studies, mostly focusing on the lack of randomization and clear definition of CAL.

\section{CAL definition, ALT methodology}

Among the inclusions, only 11 studies [5-15] provided detailed diagnostic criteria for CAL. Five studies [8-10, 16, 17] diagnosed CAL based on clinical manifestations, while eight studies [5, 7, 8, 12-14, 18, 19] provided both clinical and radiological diagnostic criteria of CAL. There were five studies [20-24] that did not provide any references with regard to the diagnosis of CAL.

Various methods of ALT tests were used in the included studies. As listed in Table 1, we found that with the exception of one study [24]. Despite the fact that all other studies reported their methods of ALT evaluation, the methods themselves varied greatly between studies. Not all studies reported the volume of the inflated gas/dye, while the reported volume varied from $60 \mathrm{~mL}$ [6] to $400 \mathrm{~mL}$ [22]. No study mentioned intraluminal pressure measurements during ALT. When a leak was observed during ALT, i.e., ALT(+), different repair methods were applied varying from reinforcing sutures up to reconstruction of the anastomosis or performing a diverting stoma [17] (Table 1).

\section{Clinical CAL rate in ALT patients vs. non-ALT patients}

As is shown in Fig. 2, nine studies reported a comparison of the clinical CAL rate between the patients with ALT and those without ALT. Although a lower CAL rate was found in the patients with ALT, no significant difference was found when compared to the patients without ALT $(P=0.15)$. The heterogeneity among the studies was significant $\left(P=0.02, I^{2}=0.55\right)$.

Subgroup analysis showed that combining the data of the LOE $1 \mathrm{~b}$ studies $[12,19]$ showed a significant difference in the CAL rate between patients with ALT and those without ALT (Fig. 3), while such difference was not significant in the LOE $2 \mathrm{~b}$ studies (Fig. 4). The combined CAL rate in the patients with ALT remained stable at 5.8, 4.7, and $4.9 \%$ in the LOE $1 \mathrm{~b}$, $2 \mathrm{~b}$, and 4 , respectively. On the contrary, the CAL rate in the patients without ALT was reported as $16 \%$ in the LOE $1 \mathrm{~b}$ studies, which was higher than the rate of $5.3 \%$ in the LOE $2 b$ trials.

\section{CAL rate in $\operatorname{ALT}(+)$ vs. ALT(-)}

As is shown in Fig. 5, the intraoperative positive rate of ALT varies among different studies (1.5 to $24.7 \%$ ). While the clinical CAL rate in those intraoperative ALT $(+)$ patients was $11.4 \%$, compared to $4.2 \%$ in ALT $(-)$ patients. The meta-analysis showed a significant difference $(P<0.001)$ between these two groups (Fig. 6), with no significant heterogeneity between studies $\left(P=0.84, I^{2}=0\right)$.

\section{Sensitivity analysis}

Except from one study, exclusion of the others had no influence on outcome significance. Exclusion of one heavily 


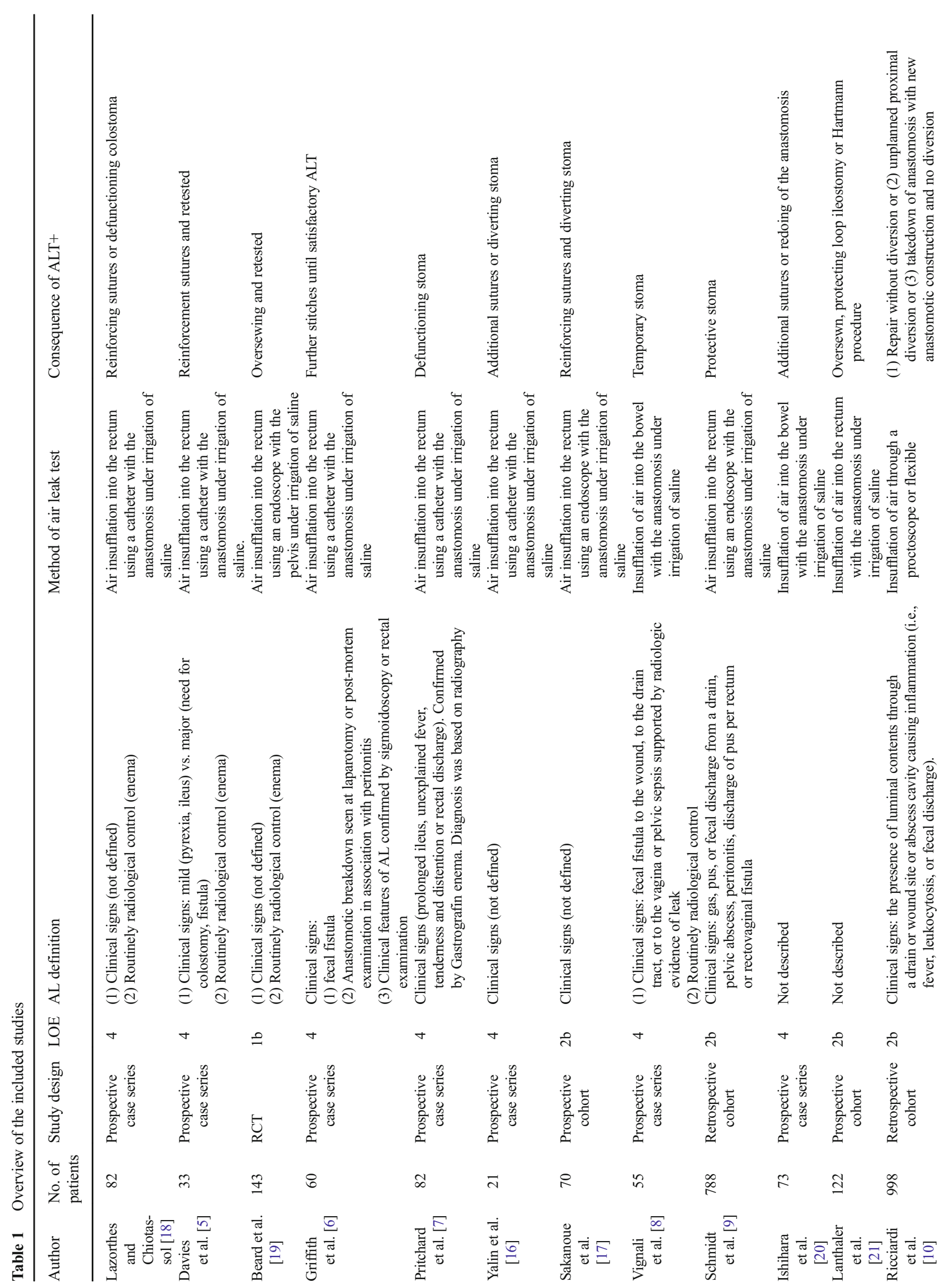




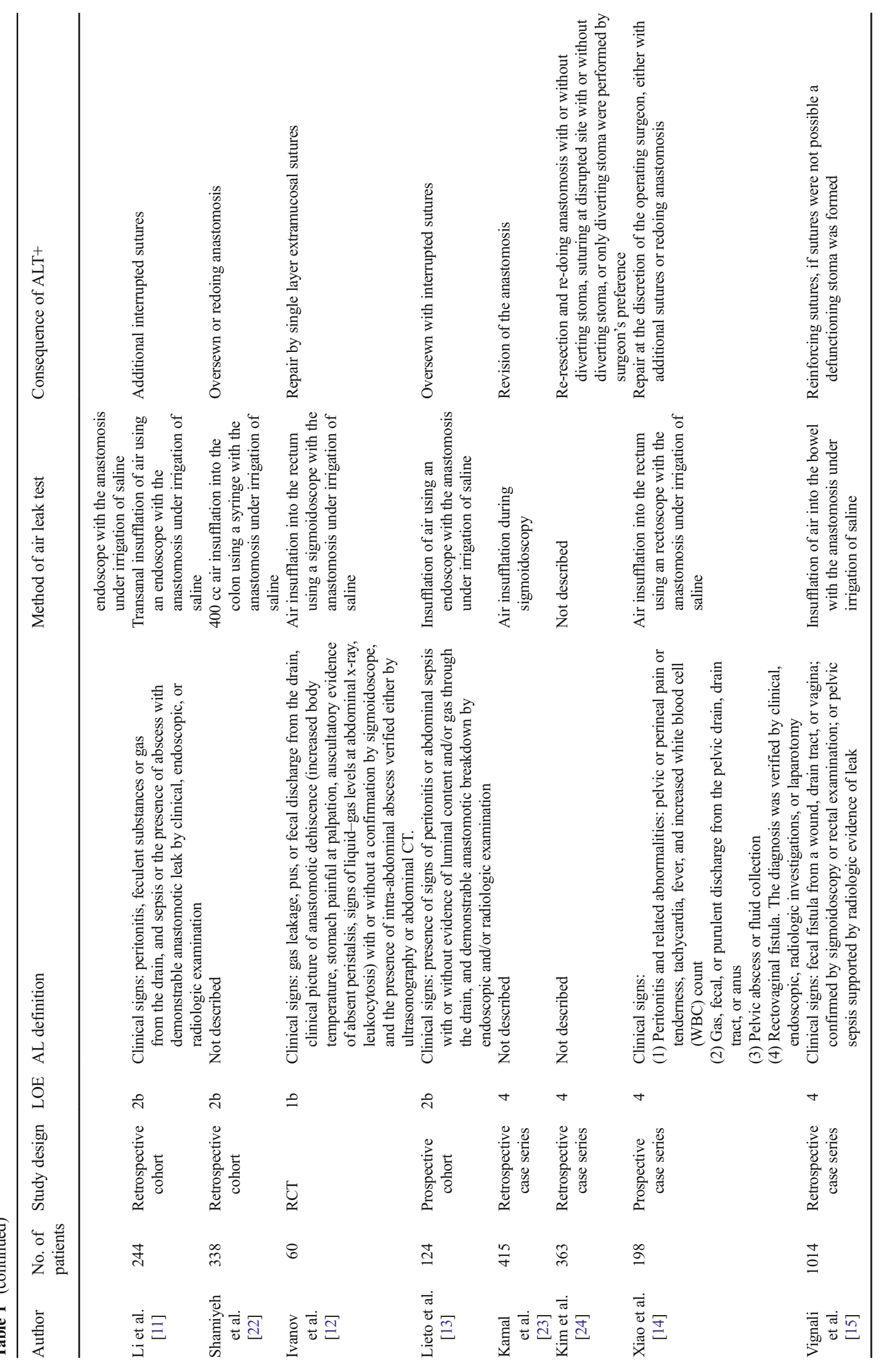


Table 2 Risk of Bias of the included studies

\begin{tabular}{|c|c|c|c|c|c|c|}
\hline Author & $\begin{array}{l}\text { Sequence } \\
\text { generation }\end{array}$ & $\begin{array}{l}\text { Allocation } \\
\text { concealment }\end{array}$ & Blinding & $\begin{array}{l}\text { Incomplete outcome } \\
\text { data }\end{array}$ & $\begin{array}{l}\text { Selective outcome } \\
\text { reporting }\end{array}$ & $\begin{array}{l}\text { Other sources } \\
\text { of bias }\end{array}$ \\
\hline Lazorthes and Chiotassol [18] & - & - & - & + & + & + \\
\hline Davies et al. [5] & - & - & - & + & + & + \\
\hline Beard et al. [19] & + & + & $?$ & + & + & + \\
\hline Griffith et al. [6] & - & - & - & + & + & + \\
\hline Pritchard et al. [7] & - & - & - & + & + & + \\
\hline Yalin et al. [16] & - & - & - & + & $?$ & + \\
\hline Sakanoue et al. [17] & - & - & - & - & $?$ & - \\
\hline Vignali et al. [15] & - & - & - & + & + & + \\
\hline Vignali et al. [8] & - & - & - & + & + & + \\
\hline Schmidt et al. [9] & - & - & - & + & + & - \\
\hline Ishihara et al. [20] & - & - & - & + & ? & + \\
\hline Lanthaler et al. [21] & - & - & - & + & + & + \\
\hline Ricciardi et al. [10] & - & - & - & + & + & + \\
\hline Li et al. [11] & - & - & - & + & + & + \\
\hline Shamiyeh et al. [22] & - & - & - & + & + & + \\
\hline Ivanov et al. [12] & + & $?$ & $?$ & + & + & + \\
\hline Xiao et al. [14] & - & - & - & + & + & + \\
\hline Lieto et al. [13] & - & - & - & + & + & + \\
\hline Kamal et al. [23] & - & - & - & + & + & + \\
\hline Kim et al. [24] & - & - & - & + & + & + \\
\hline
\end{tabular}

weighted article from Schmidt et al. [9], however, resulted in a major change in significance in the clinical CAL rate in ALT patients vs. non-ALT patients evaluation. With this article included, an OR of $0.61[0.32,1.19](P=0.15)$ was found. After exclusion, an OR of $0.46[0.29,0.74](P=0.001)$ was calculated.

\section{Discussion}

Air leak test (ALT) is the most frequent performed intraoperative test to detect mechanically insufficient colorectal anastomoses for intraoperative repair. This meta-analysis summarizes the clinical evidence regarding the application of ALT. We found that with current evidence, performing ALT has not significantly reduced the clinical CAL rate after surgery, but it remains necessary due to a significantly higher risk of CAL in patients with a positive leak during the test. The standardization of ALT in future studies is urgently needed to further verify the effectiveness of ALT and its future applications.

As is shown from our data, no significant reduction of CAL rate is seen in the meta-analysis of the CAL rates between patients who underwent ALT and those who did not. Although subgroup analysis showed a significant difference in the RCT (LOE1b) studies, the limited numbers of patients and the extraordinarily high CAL rate in the patients without ALT increase the concern with regards to the reliability of the difference. Particularly, since neither of the two LOE1b studies blinded the surgeons during postoperative investigation, the observer bias may influence the diagnosis of CAL after surgery. For future studies, it is important to ensure double blinding when performing a RCT on such topic.

In the sensitivity analysis, the primary comparison in this meta-analysis was heavily influenced by one study with a
Fig. 2 Clinical colorectal anastomotic leakage rate in air leak test (ALT) patients vs. nonALT patients

\begin{tabular}{|c|c|c|c|c|c|c|c|c|c|c|}
\hline Study or Subgroup & \multicolumn{2}{|l|}{ ALT } & Non-ALT & $\begin{array}{l}\text { ALT } \\
\text { Total }\end{array}$ & Weight & $\begin{array}{c}\text { Odds Ratio } \\
\text { IV, Random, } 95 \% \mathrm{Cl} \\
\end{array}$ & \multicolumn{4}{|c|}{$\begin{array}{c}\text { Odds Ratio } \\
\text { IV, Random, } 95 \% \mathrm{CI}\end{array}$} \\
\hline Sakanoue et al. 1993 & 0 & 35 & 4 & 35 & $4.1 \%$ & $0.10[0.01,1.90]$ & $\longleftarrow$ & & F & \\
\hline Li et al. 2009 & 1 & 137 & 1 & 107 & $4.6 \%$ & $0.78[0.05,12.61]$ & & & & \\
\hline Shamiyeh et al. 2011 & 1 & 85 & 4 & 253 & $6.6 \%$ & $0.74[0.08,6.72]$ & & & & \\
\hline Lanthaler et al. 2008 & 4 & 73 & 2 & 49 & $9.2 \%$ & $1.36[0.24,7.74]$ & & & - & \\
\hline Lieto et al. 2011 & 2 & 56 & 7 & 68 & $10.1 \%$ & $0.32[0.06,1.62]$ & & & - & \\
\hline Ivanov et al. 2011 & 3 & 30 & 6 & 30 & $11.0 \%$ & $0.44[0.10,1.97]$ & & & - & \\
\hline Beard et al. 1990 & 3 & 73 & 10 & 70 & $12.4 \%$ & $0.26[0.07,0.98]$ & & & & \\
\hline Ricciardi et al. 2009 & 34 & 825 & 14 & 173 & $20.4 \%$ & $0.49[0.26,0.93]$ & & & & \\
\hline Schmidt et al. 2003 & 27 & 260 & 32 & 528 & $21.7 \%$ & $1.80[1.05,3.07]$ & & & $-\square$ & \\
\hline Total $(95 \% \mathrm{Cl})$ & & 1574 & & 1313 & $100.0 \%$ & $0.61[0.32,1.18]$ & & & & \\
\hline Total events & 75 & & 80 & & & & & & & \\
\hline $\begin{array}{l}\text { Heterogeneity: } \mathrm{Tau}^{2}= \\
\text { Test for overall effect: }\end{array}$ & $\begin{array}{l}.45 ; \mathrm{Chi}^{2} \\
=1.46(\end{array}$ & $\begin{array}{l}=17.8 \\
P=0.1\end{array}$ & $\begin{array}{l}85, \mathrm{df}=\varepsilon \\
15)\end{array}$ & $8(P=0$ & $.02) ; 1^{2}=$ & $=55 \%$ & 0.01 & 0.1 & $\begin{array}{r}10 \\
\text { Non-ALT }\end{array}$ & 100 \\
\hline
\end{tabular}


Fig. 4 Clinical colorectal anastomotic leakage rate in air leak test (ALT) patients vs. nonALT patients: subgroup analysis LOE 2b. LOE level of evidence

\begin{tabular}{|c|c|c|c|c|c|c|c|c|c|}
\hline Study or Subgroup & $\begin{array}{r}\text { ALT } \\
\text { Events } \\
\end{array}$ & ALT & $\begin{array}{r}\text { Non-A } \\
\text { Events }\end{array}$ & $\begin{array}{l}\text { ALT } \\
\text { Total } \\
\end{array}$ & Weight & $\begin{array}{c}\text { Odds Ratio } \\
\text { IV, Random, } 95 \% \mathrm{Cl}\end{array}$ & \multicolumn{3}{|c|}{$\begin{array}{c}\text { Odds Ratio } \\
\text { IV, Random, } 95 \% \mathrm{CI}\end{array}$} \\
\hline Sakanoue et al. 1993 & 0 & 35 & 4 & 35 & $5.4 \%$ & $0.10[0.01,1.90]$ & & & - \\
\hline Li et al. 2009 & 1 & 137 & 1 & 107 & $6.0 \%$ & $0.78[0.05,12.61]$ & & & \\
\hline Shamiyeh et al. 2011 & 1 & 85 & 4 & 253 & $8.6 \%$ & $0.74[0.08,6.72]$ & & & \\
\hline Lanthaler et al. 2008 & 4 & 73 & 2 & 49 & $12.0 \%$ & $1.36[0.24,7.74]$ & & & - \\
\hline Lieto et al. 2011 & 2 & 56 & 7 & 68 & $13.1 \%$ & $0.32[0.06,1.62]$ & & & \\
\hline Ricciardi et al. 2009 & 34 & 825 & 14 & 173 & $26.5 \%$ & $0.49[0.26,0.93]$ & & & \\
\hline Schmidt et al. 2003 & 27 & 260 & 32 & 528 & $28.2 \%$ & $1.80[1.05,3.07]$ & & & - \\
\hline Total $(95 \% \mathrm{Cl})$ & & 1471 & & 1213 & $100.0 \%$ & $0.74[0.35,1.57]$ & & & \\
\hline Total events & 69 & & 64 & & & & & & \\
\hline $\begin{array}{l}\text { Heterogeneity: } \mathrm{Tau}^{2}= \\
\text { Test for overall effect: }\end{array}$ & $\begin{array}{l}.45 ; \mathrm{Chi}^{2} \\
=0.79\end{array}$ & $\begin{array}{l}=13.7 \\
P=0.4\end{array}$ & $\begin{array}{l}\text { 73, } \mathrm{df}=6 \\
\text { 3) }\end{array}$ & $6(P=$ & $.03) ; I^{2}=$ & $=56 \%$ & 0.01 & $\mathrm{ALT}^{1}$ & $\begin{array}{r}10 \\
\text { Non-ALT }\end{array}$ \\
\hline
\end{tabular}

large number of patients [9]. Exclusion of that study resulted in a significant outcome in favor of ALT application. This substantially influenced the statistical analysis and the corresponding $p$ value. Moreover, it increased the uncertainty of the actual ALT effectiveness. However, we chose to include this study in the final analysis because the reporting bias was considered to be limited in the LOE $2 \mathrm{~b}$ studies since during operation surgeons were not aware of the comparison between patients underwent ALT vs. those who did not. Of course, one possible bias in LOE 2 b studies is the selection bias: surgeons may only subject anastomoses that are likely to leak to ALT but not the firm ones, which seems also explain the similar CAL rate between patients with and without ALT. This bias does exist in many of our LOE $2 \mathrm{~b}$ inclusions, but not in the studies from Shamiyeh et al. [22] and Schmidt et al. [9], which compared historical data (without routine ALT) to recent data (with routine ALT). Our further analysis found similar results when we ruled out the selected ALT cases (data not shown).

According to the current data, whether performing ALT significantly reduces the CAL rate after surgery is, at best, inconclusive. The abovementioned limitations, together with other factors including the heterogeneity in ALT methodology and outcome measurements, might all contribute to the inconclusive results. However, such results undoubtedly sound the call for a worldwide standardization of the air leak test.

A direct explanation of our data might be that ALT is not useful in the prevention of CAL and may thus be abandoned. We, probably together with all surgeons, certainly oppose such explanation because any colorectal surgeon would have seen a mechanically failed anastomosis (e.g., anastomotic dehiscence) detected by ALT, in which the avoidance of a ALT would certainly cause catastrophic CAL. Rather than the superficial interpretation, our results have shown one clear cause of the inconclusive effect of ALT: the significantly higher CAL rate in ALT(+ ) patients demonstrates that ALT $(+)$ patients are still under higher risk of developing CAL even though a repair procedure was performed in most cases. We recognize that it is certainly reasonable to assume that ALT $(+)$ may have an even higher CAL rate without the repairing procedures. However, since ALT simply detects the mechanical insufficiency, our data at least demonstrates that the current repairing strategies in the ALT $(+)$ cases, varying from additional sutures to performing a diverting stoma, have not effectively eliminated the mechanical risks of CAL in those positive cases. The high CAL rate in $\operatorname{ALT}(+)$ patients may extensively attenuate the preventive effect of ALT, resulting in the similar CAL rate between patients with and without ALT.

Though having been performed for decades, no standardized methodology or consensus has been reached, which is confirmed by our results. The fact that one inflated $60 \mathrm{~mL}$ of air during the test while another injected $400 \mathrm{~mL}$ of saline is disturbing and raises the question whether we are performing the same ALT. Unfortunately, the results from our study are not encouraging in this regard. Despite the lack of detailed methods, intraoperative ALT resulted in a positive rate varying from 1.5 to $24.7 \%$ among different studies [11, 19]. Considering that intraoperative repair was applied in most $\operatorname{ALT}(+)$ patients, we should be aware that such a diverse range of positive rate strongly implies the possibility of overtreatment in many patients, particularly in centers with a high rate of ALT $(+)$ cases. We intended to further explore whether there is any difference among the intraoperative repairing methods in reducing postoperative CAL rate, while unfortunately such analysis was not possible with the current data since it requires much detailed information that are not reported in most inclusions.

From a biomechanical point of view, a standardized volume of the injected air or water is difficult to establish because of the variation in patients' anatomy. Thereby, pressure should be considered as a means for standardization. It is important to note that an anastomosis (either handsewn or stapled) may not sustain
Fig. 3 Clinical colorectal anastomotic leakage rate in air leak test (ALT) patients vs. nonALT patients: subgroup analysis LOE 1b. LOE level of evidence

\begin{tabular}{|c|c|c|c|c|c|c|c|c|c|c|}
\hline Study or Subgroup & \multicolumn{2}{|c|}{ ALT } & \multicolumn{2}{|c|}{ Non-ALT } & Weight & \multicolumn{2}{|l|}{ Odds Ratio } & \multicolumn{2}{|c|}{$\begin{array}{c}\text { Odds Ratio } \\
\text { IV, Random, } 95 \% \mathrm{CI}\end{array}$} & \\
\hline Beard et al. 1990 & 3 & 30 & 6 & 30 & $44.5 \%$ & $0.44[0.10,1.97]$ & & & — & \\
\hline Ivanov et al. 2011 & 3 & 73 & 10 & 70 & $55.5 \%$ & $0.26[0.07,0.98]$ & & & & \\
\hline Total $(95 \% \mathrm{Cl})$ & & 103 & & 100 & $100.0 \%$ & $0.33[0.12,0.89]$ & & & & \\
\hline Total events & 6 & & 16 & & & & & & & \\
\hline \multicolumn{7}{|c|}{$\begin{array}{l}\text { Heterogeneity: } \mathrm{Tau}^{2}=0.00 ; \mathrm{Chi}^{2}=0.29, \mathrm{df}=1(\mathrm{P}=0.59) ; \mathrm{I}^{2}=0 \% \\
\text { Test for overall effect: } Z=2.20(P=0.03)\end{array}$} & 0.01 & 0.1 ALT $^{1}$ & $\begin{array}{l}10 \\
\text { Non-ALT }\end{array}$ & 100 \\
\hline
\end{tabular}




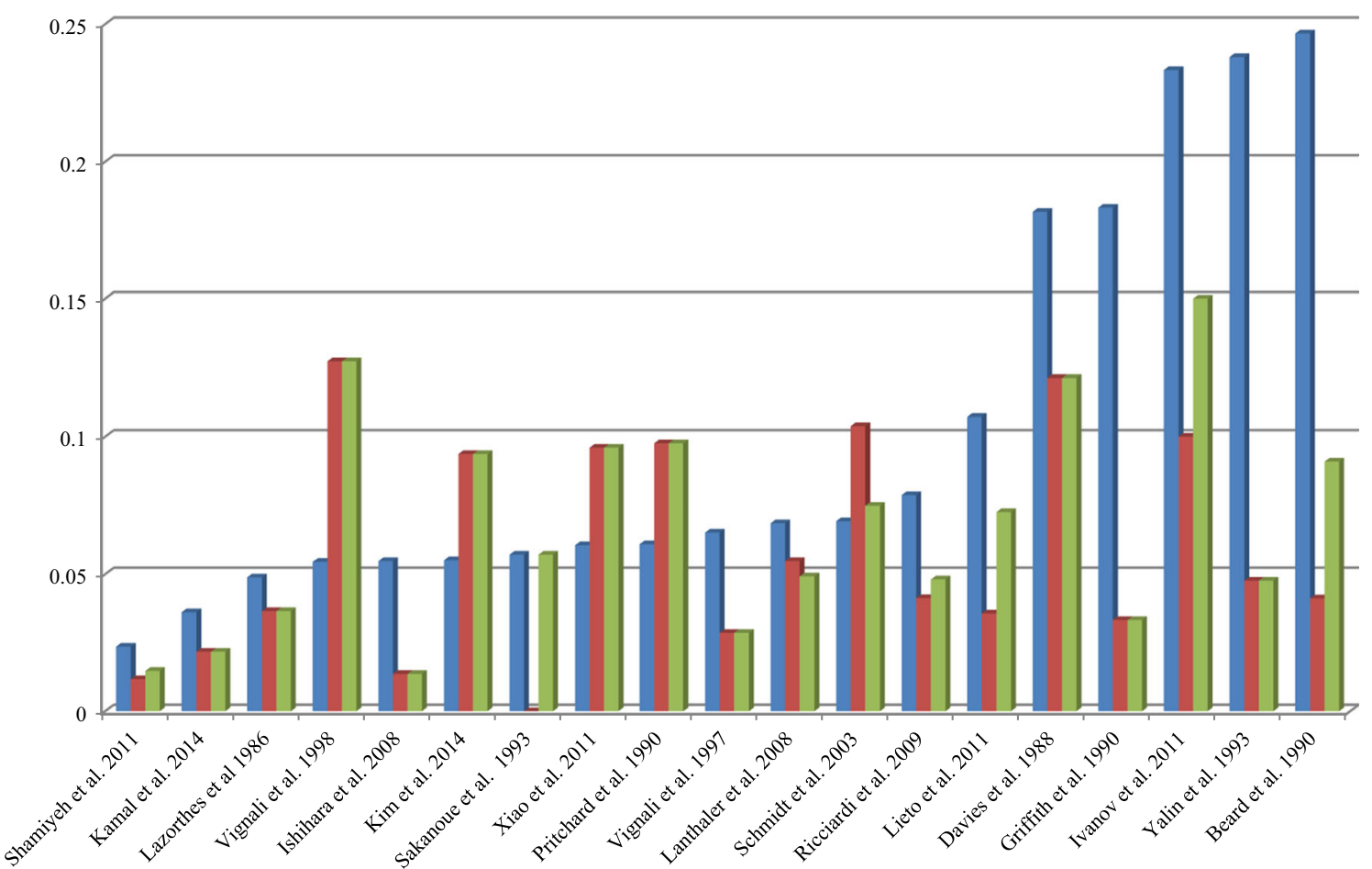

Fig. 5 Intraoperative ALT $(+)$ rate, postoperative CAL rate in ALT $(+)$ cases, and overall postoperative CAL rate. Bars in blue indicate the intraoperative positive rate of the air leak test, i.e., $\mathrm{ALT}(+)$ rate; bars in red indicate the postoperative CAL rate in the ALT $(+)$ patients; bars in green indicate the overall postoperative CAL rate in all the included patients in each study respectively. $C A L$ colorectal anastomotic leakage, $A L T$ air leak test, $A L T(+)$ indicates that leak was observed during the test intraluminal pressure as high as one may imagine. Although systematic evaluation of the burst pressure is not yet available, studies report that a newly constructed colorectal anastomosis bursts at the pressure around 70 to $184 \mathrm{mmHg}$ [25]. Compared to this pressure, injecting $400 \mathrm{~mL}$ of saline seems dangerous if not properly controlled. Therefore, a pressure indicator might be suggested during ALT. Actually, measuring the intra-luminal pressure has been included as a very standard method in measuring the early-stage anastomotic strength in animal studies [26, 27]. Although such technique is not presently available for human patients, we believe it is urgently needed. A barometer can be combined then with endoscopy or certain inflating devices to ensure a safety and ease of application.
Fig. 6 Colorectal anastomotic leakage rate in $\mathrm{ALT}(+)$ patients vs. in ALT(-) patients. CAL colorectal anastomotic leakage, $A L T$ air leak test, $A L T$ air leak test, $A L T(+)$ indicates that leak was observed during the test, $A L T(-)$ indicates that no leak was observed during the test

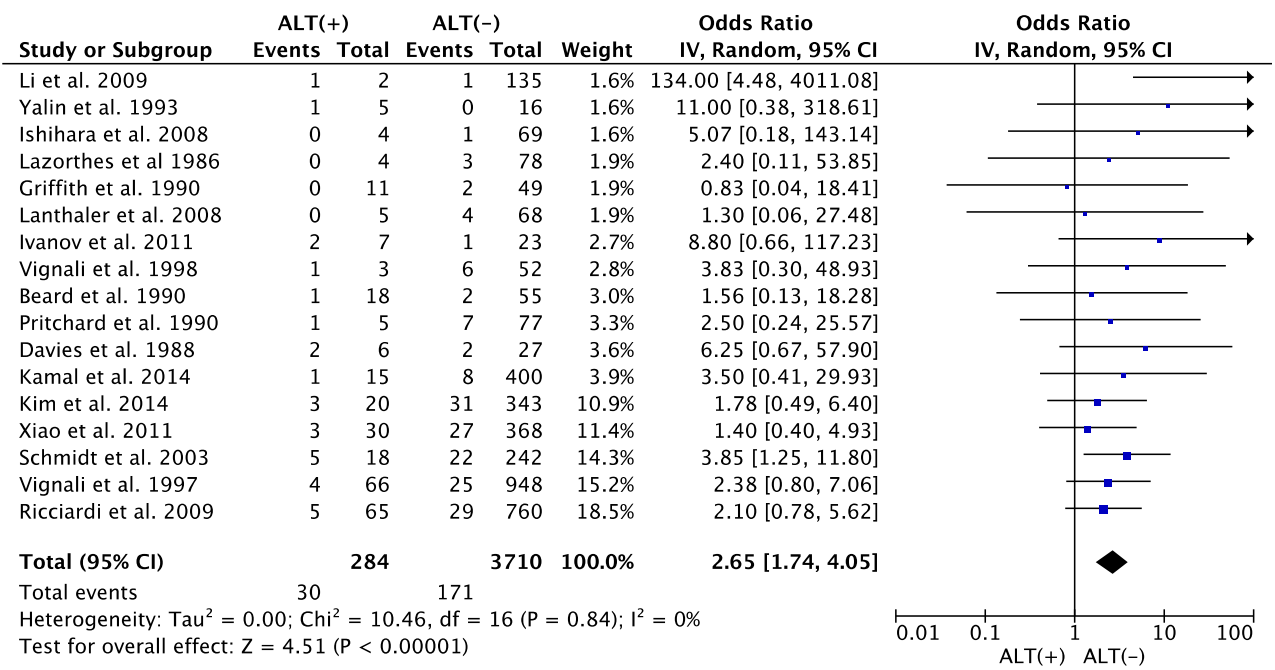




\section{Conclusion}

In conclusion, currently available evidence regarding the value of ALT in prevention of CAL contains substantial risks of bias. Based on the evidence, performing ALT with the reported methodology has not effectively reduced the clinical CAL rate after surgery. This is partly because a positive result in ALT still predicts a higher risk of postoperative CAL, and additional repairs with current methods do not decrease this risk. However, the evidence also suggests that performing ALT is necessary to identify patients with a higher risk of CAL. Being the quality control step of colorectal anastomosis, the air leak test is in dire need for worldwide standardization. Future studies with a higher level of evidence (e.g., double blinded RCT) should be initiated to verify the effectiveness of ALT.

Acknowledgments We thank Mr. W. Bramer for his kind assistance throughout the searching strategy of this review.

\section{Compliance with ethical standards}

Conflict of interests The authors declare that they have no competing interests.

Open Access This article is distributed under the terms of the Creative Commons Attribution 4.0 International License (http:// creativecommons.org/licenses/by/4.0/), which permits unrestricted use, distribution, and reproduction in any medium, provided you give appropriate credit to the original author(s) and the source, provide a link to the Creative Commons license, and indicate if changes were made.

\section{References}

1. Geoge WD (1991) Suturing or stapling in gastrointestinal surgery: a prospective randomized study. West of Scotland and Highland anastomosis study group. Br J Surg 78(3):337-341

2. Nachiappan S, Askari A, Currie A, Kennedy RH, Faiz O (2014) Intraoperative assessment of colorectal anastomotic integrity: a systematic review. Surg Endosc 28(9):2513-2530

3. Higgins JP, Altman DG, Gotzsche PC, et al. (2011) The Cochrane Collaboration's tool for assessing risk of bias in randomised trials. BMJ 343:d5928

4. Group OLoEW (2011) The Oxford 2011 levels of evidence. Oxford centre for evidence-based medicine

5. Davies AH, Bartolo DC, Richards AE, Johnson CD, McC Mortensen NJ (1988) Intra-operative air testing: an audit on rectal anastomosis. Ann R Coll Surg Engl 70(6):345-347

6. Griffith CD, Hardcastle JD (1990) Intraoperative testing of anastomotic integrity after stapled anterior resection for cancer. J R Coll Surg Edinb 35(2):106-108

7. Pritchard GA, Krouma FF, Stamatakis JD (1990) Intraoperative testing of colorectal anastomosis can be misleading. Br J Surg 77(10):1105

8. Vignali A, Gianotti L, Braga M, Radaelli G, Malvezzi L, Di Carlo V (2000) Altered microperfusion at the rectal stump is predictive for rectal anastomotic leak. Dis Colon rectum 43(1):76-82
9. Schmidt O, Merkel S, Hohenberger W (2003) Anastomotic leakage after low rectal stapler anastomosis: significance of intraoperative anastomotic testing. Eur J Surg Oncol 29(3):239-243

10. Ricciardi R, Roberts PL, Marcello PW, Hall JF, Read TE, Schoetz DJ (2009) Anastomotic leak testing after colorectal resection: what are the data? Arch Surg 144(5):407-411 discussion 411-402

11. Li VK, Wexner SD, Pulido N, et al. (2009) Use of routine intraoperative endoscopy in elective laparoscopic colorectal surgery: can it further avoid anastomotic failure? Surg Endosc 23(11):2459-2465

12. Ivanov D, Cvijanovic R, Gvozdenovic L (2011) Intraoperative air testing of colorectal anastomoses. Srp Arh Celok Lek 139(5-6): 333-338

13. Lieto E, Orditura M, Castellano P, et al. (2011) Endoscopic intraoperative anastomotic testing may avoid early gastrointestinal anastomotic complications. A prospective study. J Gastrointest Surg 15(1):145-152

14. Xiao L, Zhang WB, Jiang PC, et al. (2011) Can transanal tube placement after anterior resection for rectal carcinoma reduce anastomotic leakage rate? A single-institution prospective randomized study. World J Surg 35(6):1367-1377

15. Vignali A, Fazio VW, Lavery IC, et al. (1997) Factors associated with the occurrence of leaks in stapled rectal anastomoses: a review of 1,014 patients. J Am Coll Surg 185(2):105-113

16. Yalin R, Aktan AO, Yegen C, Dosluoglu H, Okboy N (1993) Importance of testing stapled rectal anastomoses with air. Eur J Surg 159(1):49-51

17. Sakanoue Y, Nakao K, Shoji Y, Yanagi H, Kusunoki M, Utsunomiya J (1993) Intraoperative colonoscopy. Surg Endosc 7(2):84-87

18. Lazorthes F, Chiotassol P (1986) Stapled colorectal anastomoses: peroperative integrity of the anastomosis and risk of postoperative leakage. Int J Color Dis 1(2):96-98

19. Beard JD, Nicholson ML, Sayers RD, Lloyd D, Everson NW (1990) Intraoperative air testing of colorectal anastomoses: a prospective, randomized trial. Br J Surg 77(10):1095-1097

20. Ishihara S, Watanabe T, Nagawa H (2008) Intraoperative colonoscopy for stapled anastomosis in colorectal surgery. Surg Today 38(11):1063-1065

21. Lanthaler M, Biebl M, Mittermair R, Ofner D, Nehoda H (2008) Intraoperative colonoscopy for anastomosis assessment in laparoscopically assisted left-sided colon resection: is it worthwhile? J Laparoendosc Adv Surg Tech A 18(1):27-31

22. Shamiyeh A, Szabo K, Ulf Wayand W, Zehetner J (2012) Intraoperative endoscopy for the assessment of circular-stapled anastomosis in laparoscopic colon surgery. Surg Laparosc Endosc Percutan Tech 22(1):65-67

23. Kamal T, Pai A, Velchuru V, et al. (2014) Should anastomotic assessment with flexible sigmoidoscopy be routine following laparoscopic restorative left colorectal resection? Color Dis

24. Kim JH, Kim HY, Lee IK, Oh ST, Kim JG, Lee YS (2014) Intraoperative double-stapled colorectal or coloanal anastomotic complications of laparoscopic low anterior resection for rectal cancer: double-stapled anastomotic complication could result in persistent anastomotic leakage. Surg Endosc

25. Schwab R, Wessendorf S, Gutcke A, Becker P (2002) Early bursting strength of human colon anastomoses - an in vitro study comparing current anastomotic techniques. Langenbecks Arch Surg 386(7):507-511

26. Wu Z, Vakalopoulos KA, Kroese LF, et al. (2013) Reducing anastomotic leakage by reinforcement of colorectal anastomosis with cyanoacrylate glue. Eur Surg Res 50(3-4):255-261

27. Wu Z, Boersema GSA, Kroese LF, et al. (2015) Reducing colorectal anastomotic leakage with tissue adhesive in experimental inflammatory bowel disease. Inflamm Bowel Dis 21(5):1038-1046 